\title{
Activity-Dependent Patterning of Retinogeniculate Axons Proceeds with a Constant Contribution from AMPA and NMDA Receptors
}

\author{
Carsten D. Hohnke, Serkan Oray, and Mriganka Sur \\ Department of Brain and Cognitive Sciences, Massachusetts Institute of Technology, Cambridge, Massachusetts 02139
}

\begin{abstract}
Neural activity is critical for the refinement of neural circuitry during development, although the mechanisms involved in stabilizing appropriate connectivity remain unclear. It has been proposed that the insertion of AMPA receptors at synapses with only NMDA receptors ("silent synapses") mediates this stabilization, leading to an increasing contribution from AMPA receptors as development proceeds. Here we show in a mammalian system known to undergo activity-dependent development [the segregation of retinal afferents into ON/OFF sublaminae in the ferret lateral geniculate nucleus (LGN)] that the refinement of the neural circuitry occurs in the presence of a constant functional contribution from AMPA and NMDA receptors. Although we detected a small number of silent synapses on LGN cells, their proportion did not decrease with age. The size and kinetics of NMDAmediated spontaneous EPSCs (sEPSCs) were also stable over this period. Together with previous results reporting the stability
\end{abstract}

of unitary AMPA-mediated EPSCs, the constancy of NMDAmediated sEPSCs indicates an unchanging AMPA/NMDA contribution. Additionally, the CNQX-sensitivity did not increase for either sEPSCs or optic tract-evoked EPSCs. Likewise, the anatomical AMPA/NMDA ratio, as assayed by quantifying the colocalized expression of AMPA and NMDA receptor subunits, was fixed throughout ON/OFF sublamination. In particular, the colocalization of AMPA receptor subunits (GluR1 or GluR4) and NMDA receptor subunit NR1 opposite identified retinogeniculate terminals was stable during this period. These results add to the view of the population of retinogeniculate synapses as robustly stable or normalized during a period when retinogeniculate axons are undergoing dramatic activity-dependent refinement.

Key words: visual system development; silent synapses; electrical activity; NMDA receptors; AMPA receptors; lateral geniculate nucleus
In many sensory systems, the development of appropriate neural circuitry depends critically on the presence of patterned neural activity. In the mammalian visual system, for example, both thalamic and cortical circuits are refined in an activity-dependent manner during early development (Goodman and Shatz, 1993; Cramer and Sur, 1995; Katz and Shatz, 1996; Hohnke and Sur, 1999a). However, it is not well understood how neural activity provides instruction for changes in the neural circuitry. Given the similarities between the mechanisms involved in activitydependent development and those involved in changes of synaptic efficacy [such as long-term potentiation (LTP) or long-term depression ], it has been proposed that the latter phenomenon mediates the former (Constantine-Paton et al., 1990; Kandel and O'Dell, 1992; Goodman and Shatz, 1993; Cramer and Sur, 1995; Katz and Shatz, 1996; Constantine-Paton and Cline, 1998). More specifically, it has been proposed that the conversion of so-called silent synapses to functional ones might be involved in the maintenance of LTP (Isaac et al., 1995; Liao et al., 1995), as well as in the establishment of appropriate connectivity during development (Durand et al., 1996; Wu et al., 1996; Isaac et al., 1997; Li and Zhuo, 1998; Rumpel et al., 1998; Liao et al., 1999; Petralia et al., 1999). That is, before a period of activity-dependent development, all axon branches, appropriately and inappropriately placed, make a significant number of synapses with NMDA receptors alone, and those branches are stabilized on which synapses incorporate AMPA receptors; the others are retracted.

Yet, although silent synapses may play a role in activitydependent refinement during development, they have not been investigated in a developing mammalian system that undergoes a

\footnotetext{
Received July 28, 2000; revised Aug. 16, 2000; accepted Aug. 18, 2000.

The work was supported by National Institutes of Health Grants EY 11512 and EY 07023. We thank Adrienne Sacatos for assistance with data collection in NR1/GluR1 immunocytochemistry experiments and Michael O'Boyle for assistance with confocal microscopy.

Correspondence should be addressed to Mriganka Sur, Massachusetts Institute of Technology, E25-235, 45 Carleton Street, Cambridge, MA 02139. E-mail: msur@ai. mit.edu.

Copyright (C) 2000 Society for Neuroscience $0270-6474 / 00 / 208051-10 \$ 15.00 / 0$
}

well characterized axonal reorganization. The majority of reports of silent synapses come from the hippocampus (Isaac et al., 1995; Liao et al., 1995; Durand et al., 1996; Liao et al., 1999; Petralia et al., 1999); however, to our knowledge, the activity-dependence of axonal development in that region has not been reported. Likewise, in other mammalian brain regions, the role of activity in shaping the relevant axon arbors containing precisely the synapses that were examined is unclear (see Discussion). Silent synapses have also been found in the tadpole optic tectum (Wu et al., 1996) in which activity is known to alter retinotectal afferents (Debski et al., 1990; Cline, 1991; Renteria and Constantine-Paton, 1996).

We have been investigating the development of synaptic efficacy in the ferret lateral geniculate nucleus (LGN). In the ferret, retinal projections from each eye initially overlap in the LGN but segregate within the first 2 postnatal weeks into laminae that receive inputs from only one or the other eye. In the subsequent 2 weeks, within each of the eye-specific layers, retinogeniculate axons from $\mathrm{ON}$-center and OFF-center retinal ganglion cells (RGCs) segregate further to form ON/OFF sublaminae (Hahm et al., 1991, 1999). This segregation is activity-dependent and relies on components that are also required for the modification of synaptic strength (Cramer and Sur, 1995; Hohnke and Sur, 1999a). Here we investigate the development of silent synapses and, more generally, the AMPA/NMDA contribution during ON/OFF sublamination. Our results show that sublamination proceeds with a stable AMPA/ NMDA contribution, as assessed through multiple measures.

Parts of this work have been published previously in abstract form (Hohnke and Sur, 1999b; Oray et al., 1999).

\section{MATERIALS AND METHODS}

Electrophysiology. Thalamic slices $(400-\mu \mathrm{m}$-thick) were prepared from young [postnatal day 14 (P14) to P31] ferrets. Animals were deeply anesthetized with sodium pentobarbital ( $35 \mathrm{mg} / \mathrm{kg}$, i.p.) and decapitated. A block of tissue including the thalamus was rapidly removed and placed in a cold solution $\left(4^{\circ} \mathrm{C}\right.$ ) containing (in $\mathrm{mM}$ ): $210-252$ sucrose, $3 \mathrm{KCl}, 2-3$ $\mathrm{MgSO}_{4}, 25 \mathrm{NaHCO}_{3}, 1 \mathrm{NaHPO}_{4}, 1-2.5 \mathrm{CaCl}_{2}, 10$ dextrose, and $0.5-5$ kynurenic acid, saturated with $95 \% \mathrm{O} 2-5 \% \mathrm{CO}_{2}, \mathrm{pH}$ 7.4. The cortex was dissected away, and the remaining thalamus was sliced in the horizontal plane with a Vibratome (model 1000; Ted Pella Inc., Redding, CA). Slices were allowed to recover at room temperature in artificial CSF (ACSF) 
containing (in mM): $126 \mathrm{NaCl}, 3 \mathrm{KCl}, 2 \mathrm{MgSO}_{4}, 25 \mathrm{NaHCO}_{3}, 1 \mathrm{NaHPO}_{4}$, $2.5 \mathrm{CaCl}_{2}$, and 10 dextrose, saturated with $95 \% \mathrm{O} 2-5 \% \mathrm{CO}_{2}, \mathrm{pH} 7.4$. Slices were transferred to a submersion chamber and continuously perfused with ACSF. Recordings were performed at room temperature under visual control with infrared-differential interference contrast microscopy and were made from relay cells in the A and A1 laminae, the borders of which were clearly visible. In all experiments, $50 \mu \mathrm{M}$ bicuculline methiodide (Sigma, St. Louis, MO) was present in the ACSF. 6-Cyano-7nitroquinoxaline-2,3-dione (CNQX) $(10 \mu \mathrm{M}$; Sigma) and $50 \mu \mathrm{M}$ D-2-amino5-phosphonopentanoic acid (Sigma) were used to block AMPA and NMDA currents, respectively. Patch pipettes contained (in mM): 105 cesium gluconate, 10 HEPES, 1 sodium EGTA, $0.1 \mathrm{CaCl}_{2}, 2 \mathrm{MgCl}_{2}, 2$ Na-ATP, $0.1 \mathrm{Na}-\mathrm{GTP}$, and $5 \mathrm{QX}-314$; the $\mathrm{pH}$ was adjusted to 7.3. Retinal afferents were stimulated at $0.2 \mathrm{~Hz}$ by delivering constant current through a bipolar stimulating electrode positioned in the optic tract at the lateral edge of the slice. For minimal stimulation, appropriate stimulus intensities were based on those used in previous investigations of minimal or singlefiber stimulation (Raastad et al., 1992; Stevens and Wang, 1994). Briefly, a stimulus intensity was sought that (1) initially resulted in both EPSCs and failures, (2) produced constant EPSC latencies, and (3) did not produce EPSCs of significantly different amplitudes than those intensities just less than or greater to it [that is, the minimal response was stable over a range $(\sim 5-10 \%)$ of stimulus intensities]. For nonminimal stimulation, stimulus strength was set at the value just greater than that which produced no failures. Recordings, voltage-clamped at -60 or $+40 \mathrm{mV}$, were obtained with an Axopatch-200 amplifier (Axon Instruments, Foster City, CA), and data were acquired with pClamp (Axon Instruments) and analyzed using Matlab (MathWorks Inc., Natick, MA). Series resistances were $19.8 \pm 10.0$ $\mathrm{M} \Omega$. Cells that showed overshooting action potentials and that had resting membrane potentials more hyperpolarized than $-40 \mathrm{mV}$ were considered for analysis. Spontaneous EPSCs (sEPSCs) were automatically detected and analyzed as described previously (Hohnke and Sur, 1999b). Evoked EPSCs were analyzed similarly. Data are expressed as median, mean \pm SEM. The Mann-Whitney $U$ test, Spearman rank correlation, and Kruskal-Wallis nonparametric ANOVA were used for tests of significance unless otherwise noted.

Eye injections. Animals were treated subcutaneously with atropine $(0.1$ $\mathrm{mg} / \mathrm{kg}$ in $9 \%$ saline) and then deeply anesthetized with isoflurane $(2 \%)$ in a nitrous oxide $(60 \%)$ and oxygen $(40 \%)$ mixture. A small surgical blade was used to separate the eyelids to expose the conjunctiva on the lateral side of the eye. A $50 \mu \mathrm{l}$ Hamilton microsyringe was then used to inject 10 $\mu \mathrm{l}$ of the anterograde tracer cholera toxin subunit $\mathrm{B}(\mathrm{CTB})\left(1 \% \mathrm{H}_{2} \mathrm{O}\right.$; List Biologic, Campbell, CA) into the eye. After eye injection, the eyelids were allowed to reclose, and an antibiotic ophthalmic ointment was applied. A $2 \mathrm{~d}$ survival period was allowed for axonal transport of the CTB to the LGN.

Immunostaining. Animals were deeply anesthetized with sodium pentobarbital $(35 \mathrm{mg} / \mathrm{kg})$ and perfused transcardially with isotonic saline, followed by $4 \%$ paraformaldehyde. The brain was removed, post-fixed for 24 $\mathrm{hr}$, transferred to $30 \%$ sucrose for $24 \mathrm{hr}$, and then sectioned horizontally at $50 \mu \mathrm{m}$. Sections were blocked and permeabilized with $0.5 \%$ Triton X-100 for $30 \mathrm{~min}$ in normal sera, incubated with primary antibodies for $48 \mathrm{hr}$ at $4^{\circ} \mathrm{C}$, and subsequently incubated with secondary antibodies for $2 \mathrm{hr}$ at room temperature. Sections were then mounted in buffer, coverslipped, and sealed. The following antibodies were used: mouse anti-NMDA receptor subunit 1 (NR1) (1:250; PharMingen, San Diego, CA) (Catalano et al., 1996), rabbit anti-glutamate receptor subunit 1 (GluR1) (1:1000; Upstate Biotechnology, Lake Placid, NY) (Carder, 1997), rabbit anti-GluR4 (1:100; Chemicon, Temecula, CA) (Jones et al., 1998), goat anti-CTB (1: 1000; List Biologic) (Angelucci et al., 1996), mouse anti-synaptophysin (1:10; Boehringer Mannheim, Indianapolis, IN) (Voigt et al., 1993), horse antimouse FITC (1:200; Vector Laboratories, Burlingame, CA), goat anti-rabbit Texas Red (1:200; Vector Laboratories), and donkey anti-goat Cy5 (1:200; Chemicon). The specificity of the secondary antibodies was confirmed by omitting the primary antibodies; in all such control experiments, no fluorescence was observed.

Confocal microscopy. Confocal scanning microscopy was performed using a Bio-Rad (Hercules, CA) MRC 1024ES system on a Zeiss (Oberkochen, Germany) Axioplan microscope. All images were collected with a Zeiss Plan-Neofluar $100 \times$ oil-immersion objective with numerical aperture 1.3. Fluorescence images were obtained with a krypton-argon laser with three standard lines of excitation at 488 (FITC), 568 (Texas Red), and 647 (Сy5) $\mathrm{nm}$ with standard filters. The theoretical analog focal resolution limit (using the full-width half-maximum criterion) for our confocal apparatus at these wavelengths was $0.16,0.19$, and $0.21 \mu \mathrm{m}$, respectively (Stelzer, 1995). Because we extensively used long wavelengths of light (for visualizing Texas Red and Cy5), we chose to limit our images to a pixel resolution of $0.21 \mu \mathrm{m}$. Electron microscopy studies in the $\mathrm{A}$ and A1 laminae of the cat LGN (Wilson et al., 1984; Hamos et al., 1987) suggest that the distance between the closest excitatory glutamatergic synapses of retinal or cortical origin is on the order of $1 \mu \mathrm{m}$, indicating that a pixel resolution of $0.21 \mu \mathrm{m}$ is adequate to resolve adjacent excitatory synapses even with discrete sampling of the image. Similarly, the z-resolution (axial resolution) is limited by numerical aperture and wavelength (for instance, at an excitation wavelength of $488 \mathrm{~nm}$, the z-resolution limit is $0.42 \mu \mathrm{m}$ and gets poorer at longer wavelengths). By reducing the iris aperture, we were able to reduce the optical section thickness to $0.38 \mu \mathrm{m}$. This axial resolution was chosen to maximize signal intensity and minimize optical thick- ness. Thus, each confocal image represented a focal region of $108.3 \times 108.3$ $\mu \mathrm{m}$ with an axial thickness of $0.38 \mu \mathrm{m}(512 \times 512$ pixels with eight-bit pixel depth). Images in the separate fluorescent channels were collected sequentially and were the average of five frames at a single focal plane. All images were taken from the A or A1 layers of the LGN.

Image analysis. For double-labeling experiments, each image was analyzed independently for high-intensity activity in the FITC and Texas Red channels by a thresholding procedure. Colocalization of the two fluorescent signals was quantified as the number of pixels that had high-intensity values in both the FITC and Texas Red channels. Black and white colocalization images were generated to show the spatial distribution of colocalization with each black pixel representing a colocalization event. In triple-labeling experiments, the $\mathrm{Cy} 5$ signal (corresponding to CTB labeling of retinogeniculate terminals) was thresholded and used to restrict the region of analysis for the FITC and Texas Red signals. This was accomplished by discarding from the analysis all pixels that were more than three pixels $(0.63 \mu \mathrm{m})$ distant from the edge of high-intensity (thresholded) CTB staining. These restricted images were then analyzed for colocalization by counting the number of pixels with high-intensity values in both the FITC and Texas Red channels. Clustering was assessed by sliding a window across the colocalization image and calculating the distance of a random data point from its nearest neighbor and comparing it with the distance between a random nondata point and its nearest data point. The clustering index was generated by taking the median of the ratio of these two numbers after multiple iterations (Ruthazer and Stryker, 1996).

\section{RESULTS}

\section{Silent synapses on LGN cells}

To examine the development of silent synapses, we used minimal stimulation techniques to compare failure rates at hyperpolarized $(-60 \mathrm{mV})$ and depolarized $(+40 \mathrm{mV})$ membrane potentials. Additionally, we compared the frequency of sEPSCs in the two conditions. Because silent synapses are active only at depolarized potentials, the failure rates at those potentials should decrease relative to failure rates at hyperpolarized potentials if silent synapses are present (Isaac et al., 1995; Liao et al., 1995). Likewise, the frequency of sEPSCs would be expected to increase at depolarized potentials. Figure 1 shows the results from a typical experiment. Responses at $-60 \mathrm{mV}$ were fast with no extended decay that would result from the activation of NMDA receptors (Fig. 1C). Indeed, responses at $-60 \mathrm{mV}$ were completely blocked by CNQX (data not shown). At $-60 \mathrm{mV}$, stimulation of the optic tract resulted in failures on $60 \%$ of the trials, whereas at $+40 \mathrm{mV}$ failures occurred on $50 \%$ of the trials (Fig. $1 B$ ). This particular example suggests that any systematic difference in the reliability of transmission at the two potentials is likely to be slight.

More generally, the population data show a slight but significant decrease in the failure rate at $+40 \mathrm{mV}(39.7 \pm 2.0 \%)$ relative to $-60 \mathrm{mV}(64.4 \pm 2.0 \% ; n=14 ; p<0.05)$ (Fig. $2 A)$. The difference between failure rates at the two potentials (Fig. $2 B$ ) was equivalent before ON/OFF sublamination at P14-P17 $(26.7 \pm 3.5 \% ; n=5)$ and after its completion at P28-P31 (23.6 $\pm 4.1 \% ; n=9 ; p>0.05)$. Whereas the decrease in the failure rate at $+40 \mathrm{mV}$ at either the younger or older ages indicates the presence of some silent synapses at all ages, we find no evidence for a greater proportion at the younger ages. Figure $2 C$ shows example recordings from the same cell presented in Figure 1 . The absence of a significant increase in the sEPSC frequency at $+40 \mathrm{mV}$ suggests that the number of silent synapses onto that cell is relatively small. In neither the younger nor the older cells was sEPSC frequency increased at $+40 \mathrm{mV}$. At a holding potential of $-60 \mathrm{mV}$, the sEPSC frequencies in younger cells was $0.53 \mathrm{~Hz}(0.59 \pm 0.04 \mathrm{~Hz} ; n=7)$ and in older cells was 0.38 $\mathrm{Hz}(0.53 \pm 0.04 \mathrm{~Hz} ; n=9)$. These frequencies were no different from those recorded at $+40 \mathrm{mV}$ for either the younger $(0.40,0.45 \pm$ $0.03 \mathrm{~Hz} ; p>0.05)$ or the older $(0.35,0.37 \pm 0.02 \mathrm{~Hz} ; p>0.05)$ cells (Fig. 2D). The sEPSC frequency data thus do not indicate the presence of silent synapses and further indicate that there is no change in the efficacy of voltage-dependent synaptic transmission as $\mathrm{ON} / \mathrm{OFF}$ sublamination is established.

Silent synapses may be an extreme example of a mechanism that modulates synaptic strength by changing the receptor complement at synapses. A probe limited to the detection of silent synapses would not detect a more subtle change in the AMPA/NMDA contribution. Previously we have shown that the AMPA compo- 


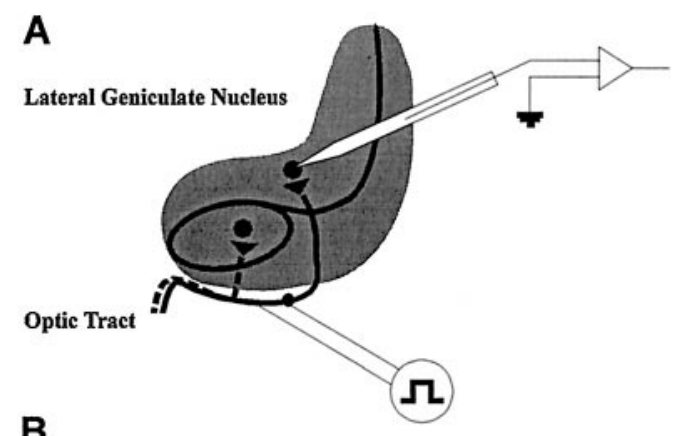

B
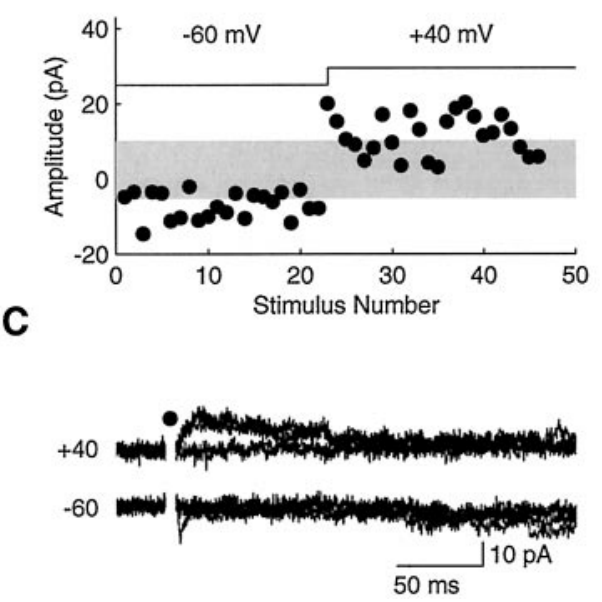

Figure 1. Typical minimal stimulation recording. A, Diagram of the experimental preparation. The stimulating electrode was placed in the optic tract along the lateral edge of horizontal LGN slices. Recordings were made in the A or A1 laminae. $B$, Individual single-fiber EPSC amplitudes at hyperpolarized and depolarized membrane potentials (indicated at the top). The gray horizontal band indicates the approximate range of noise; EPSC amplitudes falling within it are considered failures. Note the small reduction in the number of failures at $+40 \mathrm{mV}$. $C$, Five consecutive responses at -60 (bottom) and +40 (top) $\mathrm{mV}$. Responses were easily detectable over the noise. Same cell as in $B$. The filled circle represents the removal of the stimulus artifact for clarity.

nent, as assayed by AMPA receptor-mediated sEPSCs, remains stable throughout ON/OFF sublamination (Hohnke and Sur, 1999c). Here we extend those results by examining the development of NMDA receptor-mediated sEPSCs during this period to obtain a finer assessment of the development of the AMPA/ NMDA contribution.

\section{EPSCs mediated by NMDA receptors}

By depolarizing cells to $+40 \mathrm{mV}$ and adding the AMPA receptor blocker CNQX to the bath, we recorded NMDA-mediated sEPSCs from animals between P14 and P31, spanning the period of ON/ OFF sublamination. Typical distributions of areas and the averaged NMDA-mediated sEPSCs from single cells before and after ON/OFF sublamination are shown in Figure 3. Although variable, the NMDA-mediated sEPSC properties of our cell population were stable throughout ON/OFF sublamination. The charge transfer of NMDA-mediated sEPSCs (Fig. 4A), for example, was not correlated with age $(r=-0.24 ; n=16 ; p>0.05)$. More specifically, NMDA-mediated sEPSC area in the younger cells (age less than

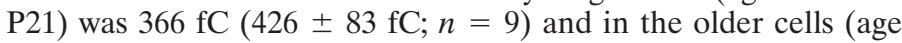
more than P28) was $373 \mathrm{fC}(477 \pm 116 \mathrm{fC} ; n=7 ; p>0.05)$. Neither was the frequency of NMDA-mediated sEPSCs correlated with age during retinogeniculate axon reorganization $(r=-0.23 ; p>$ $0.05)$. Whereas the frequency showed a slight upward trend toward the end of sublamination, the frequency in the younger cells $(0.28$, $0.16 \pm 0.06 \mathrm{~Hz})$ was not significantly different from that in older cells $(0.50,0.19 \pm 0.04 \mathrm{~Hz} ; p>0.05)$ (Fig. $4 B$ ).

Similarly, the kinetics of NMDA-mediated sEPSCs that are present at the completion of ON/OFF sublamination have been established before its onset. Rise times $(r=0.16)$, half-widths $(r=$ $-0.18)$, and decay times $(r=-0.16)$ were fixed throughout this period and did not correlate with age ( $p>0.05$ for all measures). Rise times in younger cells $(4.0,5.1 \pm 0.9 \mathrm{msec})$ were not significantly different from those in older cells $(4.6,4.7 \pm 0.6 \mathrm{msec} ; p>$ 0.05) (Fig. 4C). Likewise, half-widths in the younger cells (114, $116 \pm 14 \mathrm{msec})$ were unchanged in older cells $(97,98 \pm 9 \mathrm{msec} ; p>$ $0.05)$. Finally, the long decay times characteristic of NMDAmediated currents were similar in the younger $(124,147 \pm 19 \mathrm{msec})$ and older $(118,123 \pm 13 \mathrm{msec} ; p>0.05)$ (Fig. $4 D)$ cells. Together with previous results describing a uniform AMPA receptormediated component during this same period (Hohnke and Sur, 1999c), the stability of NMDA-mediated sEPSCs suggests an unvarying contribution of AMPA and NMDA receptors to synaptic transmission during $\mathrm{ON} / \mathrm{OFF}$ sublamination.

For a more direct assessment of the AMPA/NMDA contribution, we compared the AMPA and NMDA components of sEPSCs in the same cell. We recorded sEPSCs at $+40 \mathrm{mV}$ in control and CNQX solutions and measured their CNQX-sensitivity during and after ON/OFF sublamination. Blocking AMPA receptors would leave NMDA receptor-mediated responses and hence would be expected to reduce spontaneous (or evoked, see below) EPSC amplitude and increase the rise time; if there are proportionately more AMPA receptors in older animals, the effect of blocking AMPA receptors would be greater. Spontaneous EPSCs showed the expected effects in the presence of CNQX (Fig. 5A), but these effects were not age-dependent. Considering all cells, normalized sEPSC rise times (rise time/amplitude, which is the inverse of EPSC slope) in CNQX were $114 \%(137 \pm 22 \%)$, and amplitudes were $91 \%(91 \pm 9 \%)$ of control. In younger (P14-P16) cells, normalized sEPSC rise times in CNQX were $125 \%(160 \pm 51 \%$; $n=9)$ and in older (P28-P31) cells were 110\% (109 $\pm 15 \% ; n=$ 7) of control. However, there was no significant difference in the effect of CNQX, and therefore in the AMPA/NMDA ratio, between the younger and older cells $(p>0.05)$ (Fig. $5 B)$.

Relay cells in the LGN receive input from several sources other than retinal ganglion cell axons, although the principal glutamatergic inputs are retinal or cortical in origin (Sherman and Koch, 1986, 1998). Although it has been demonstrated that evoked, miniature, retinogeniculate EPSCs are indistinguishable from sEPSCs in this system (Hohnke and Sur, 1999c), it is not clear whether the sEPSCs recorded in the present study arise from corticogeniculate or retinogeniculate inputs. Replacing calcium with strontium in the extracellular solution to evoke miniature EPSCs (mEPSCs) of identified origin (Miledi, 1966; Goda and Stevens, 1994; Oliet et al., 1996), as we have done in our examination of AMPA-mediated retinogeniculate mEPSCs (Hohnke and Sur, 1999c), is problematic when investigating NMDA currents because their decay times are longer than the intervals between asynchronous transmitter release. To more specifically assay the AMPA/NMDA contribution at retinogeniculate synapses, we investigated the CNQX-sensitivity of optic tract-evoked EPSCs. Optic tract stimulation in control and CNQX conditions also suggests that no developmental change occurs in the AMPA/NMDA contribution during ON/OFF sublamination. After the addition of CNQX, normalized rise times of evoked EPSCs in the younger $(n=5)$ cells were $159 \%(182 \pm$ $54 \%)$ and in the older $(n=4)$ cells were $204 \%(205 \pm 26 \%)$ of control. As with sEPSCs (but based on a small population of cells in each group), there was no significant difference between the younger and older cells in the effect of CNQX $(p>0.05)$, consistent with no change in the NMDA-mediated response with age and in the AMPA/NMDA contribution (Fig. 5D).

\section{Colocalization of AMPA and NMDA receptor subunits}

To further investigate the development of the AMPA/NMDA contribution during ON/OFF sublamination, we examined the colocalized expression of AMPA and NMDA glutamate receptor subunits. If AMPA receptors are progressively inserted at NMDAonly synapses, we would observe an increase in the colocalization of AMPA and NMDA receptors. At P14, we observed labeling of 
A

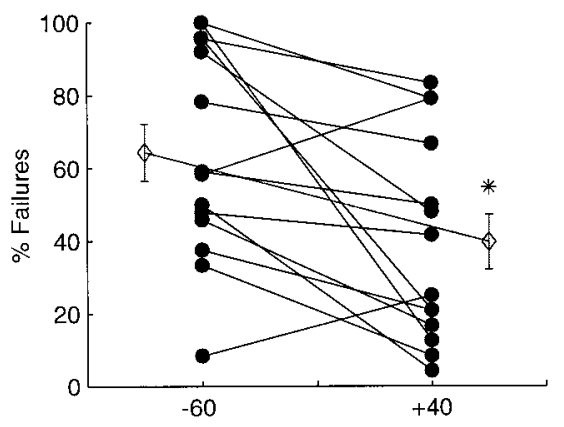

Figure 2. A small number of silent synapses are present during $\mathrm{ON} / \mathrm{OFF}$ sublamination, but their proportion is constant before and after sublamination. $A$, Failure rates at -60 and +40 $\mathrm{mV}$ for individual cells. The outside markers are the means for the two conditions. $B$, Failure rates by age at -60 and $+40 \mathrm{mV}$. The slight decrease in failure rates at $+40 \mathrm{mV}$ is equivalent at P14-P17 (at the onset of sublamination; filled bars) and P28-P31 (after its completion; open bars). C, Spontaneous EPSCs recorded at -60 (bottom) and +40 (top) $\mathrm{mV}$. Note the absence of a dramatic increase in the number of sEPSCs at $+40 \mathrm{mV}$. Same cell as in Figure 1. $D$, The frequency of sEPSCs was not significantly decreased at $+40 \mathrm{mV}$, suggesting that the results from $B$ are attributable to a small rather than large number of silent synapses. Data are mean \pm SEM. Denotes $* p<0.05$.
B

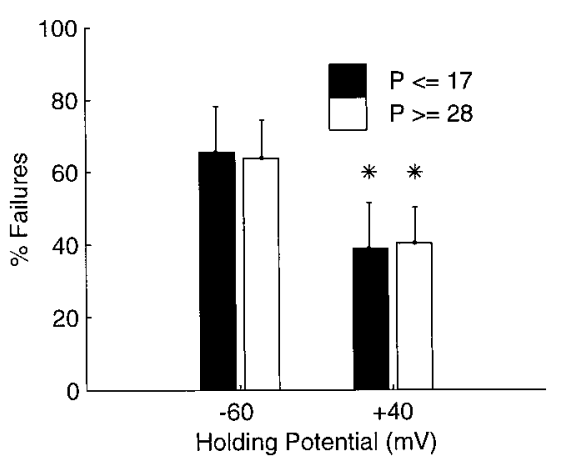

C

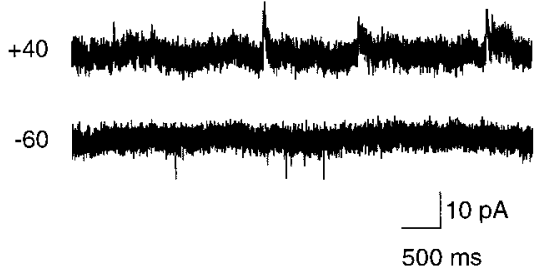

D

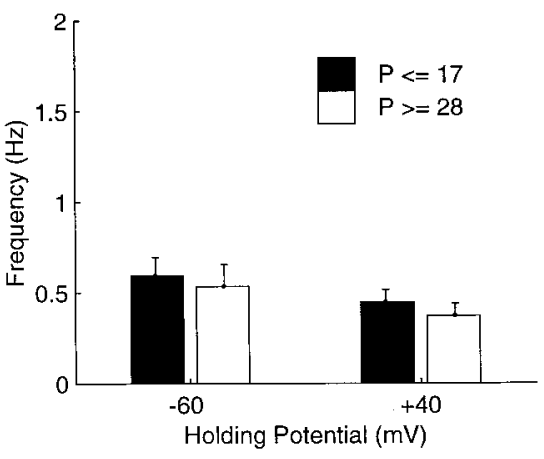

both NR1, an obligatory NMDA receptor subunit, and GluR1, an AMPA receptor subunit, which continued through P28 (Fig. 6A). There was significant overlap of the label for both subunits, and their colocalization was constant throughout sublamination $(n=51$ images from 9 animals; $p>0.05$ ) (Fig. $6 B$ ).

Our immunostaining technique does not differentiate between intracellular and extracellular subunit expression (Mammen et al., 1997). Consequently, colocalization values may be skewed by changes in production of the various subunits at locations nearby one another (e.g., the cell body). That is, an increase in colocalization at synapses may be masked by a decrease in receptor subunit translation in the nucleus. If this were the case, one would expect to see a decrease in the clustering of colocalized pixels, corresponding to the decrease at the soma. To address this issue, we performed a cluster analysis (see Materials and Methods). The clustering of GluR1 and NR1 is similar before and after ON/OFF
Figure 3. Representative histograms of NMDA-mediated SEPSC areas (recorded at $+40 \mathrm{mV}$ with CNQX in the bath) for a P14 $(A$, left $)$ and a P31 $(B$, left) cell; diamonds indicate the median values. Note the similar appearance and median values of the distributions. Short and long time scale recordings from the same cells (right) show similar amplitudes and shapes at the two ages that are before and after ON/OFF sublamination, respectively.
A

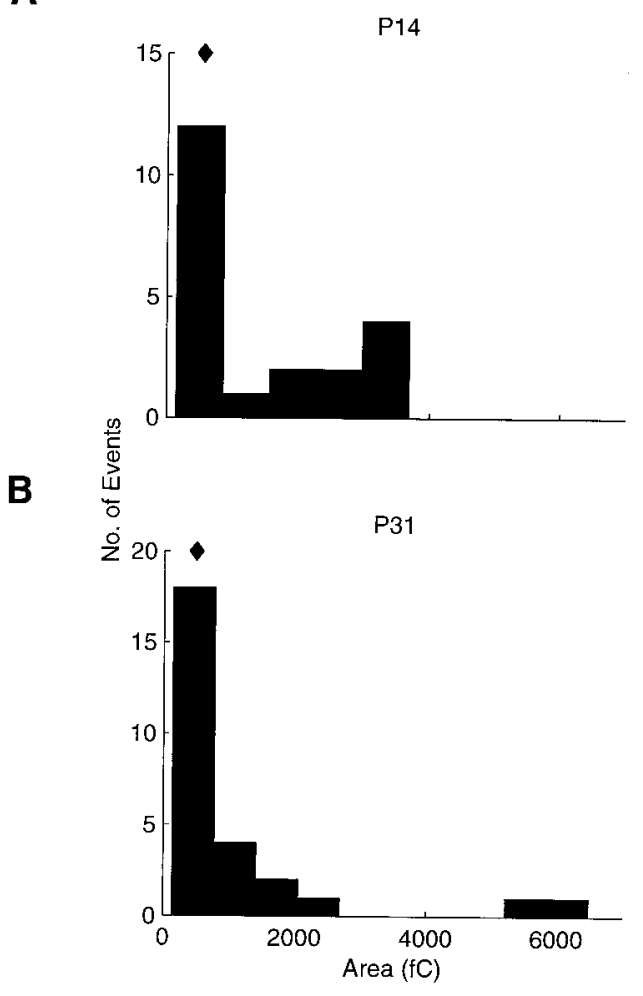

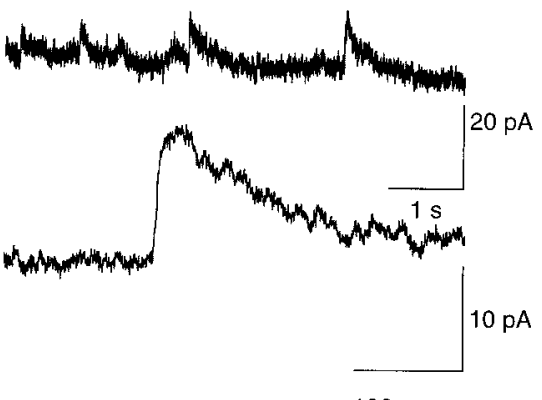

$100 \mathrm{~ms}$ 
A

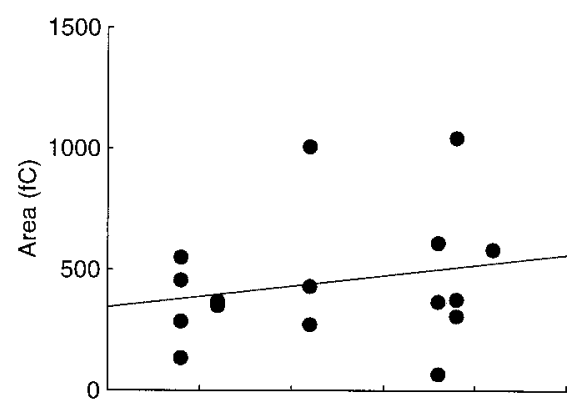

C

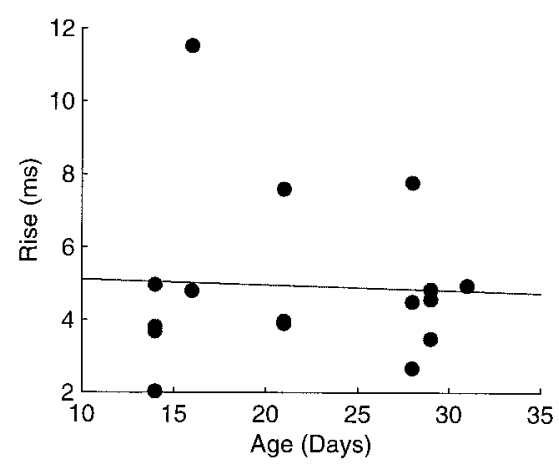

B

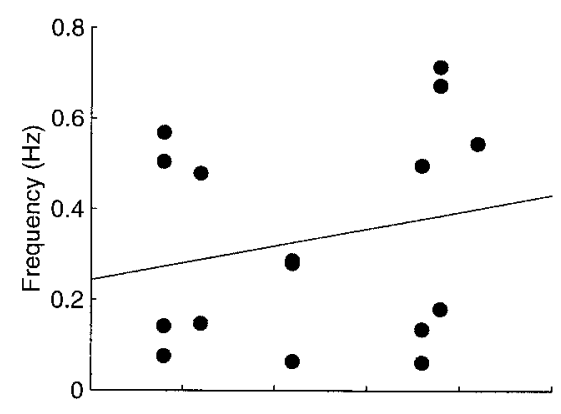

D

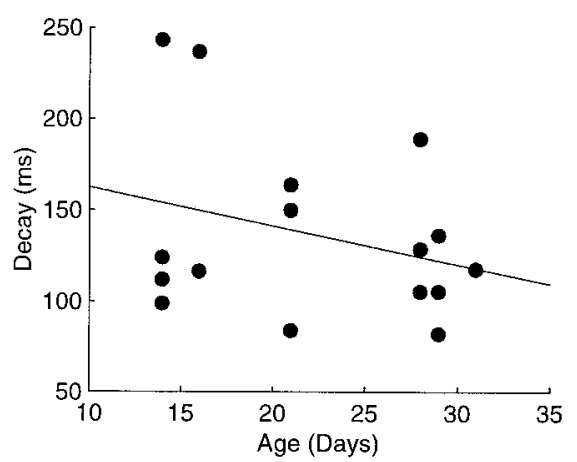

Figure 4. The properties of NMDAmediated sEPSCs are stable throughout ON/OFF sublamination. Scatter plots of the size $(A)$, frequency $(B)$, and kinetics $(C, D)$ of NMDA-mediated sEPSCs throughout ON/OFF sublamination. None of the properties are correlated with age during this period $(p>0.05)$. sublamination $(p>0.05)$, although it increases from $\mathrm{P} 14$ to $\mathrm{P} 21$ $(p<0.05)$ (Fig. $6 C)$.

Unlike NMDA receptors, AMPA receptors do not include an obligatory subunit. Consequently, to determine whether the pattern of colocalization that we observed was in some way unique to the GluR1 subunit, we repeated the double-labeling experiments with antibodies to the GluR4 subunit. The development of GluR4NR1 colocalization during ON/OFF sublamination was similar to that observed with GluR1-NR1 labeling (Fig. 7A). That is, colocalization of GluR4 and NR1 at P14, P21, and P28 was stable $(n=$
38 images from 9 animals; $p>0.05$ ) (Fig. 7B). As with GluR1-NR1 labeling, GluR4-NR1 clustering at the end of sublamination was not significantly changed from that before its onset $(p>0.05)$, although it did increase at P21 $(p<0.05)$ (Fig. 7C). Interestingly, at later ages (P21 and P28), we observed neurons that expressed NR1 but did not express high levels of the GluR1 subunit. In contrast, we observed no neurons at any age that expressed NR1 but did not express GluR4. This may suggest that GluR4 is a more stable and ubiquitous AMPA receptor subunit in the developing ferret LGN.
A

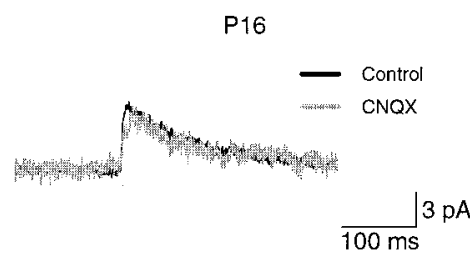

P29

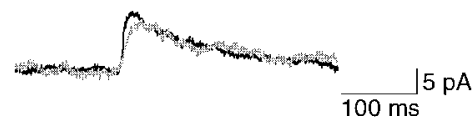

B

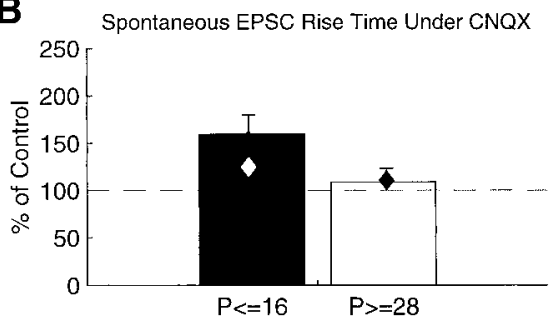

C
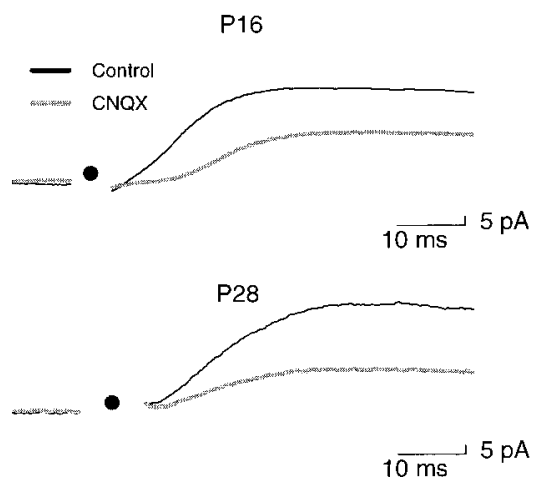

D

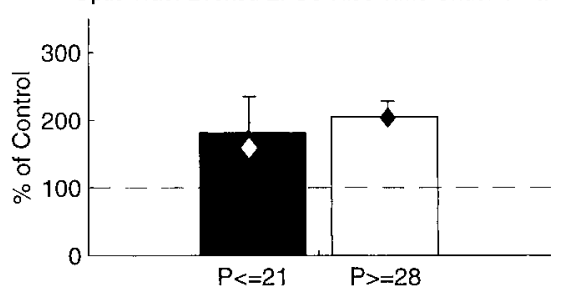

Figure 5. NMDA-mediated sEPSC and evoked EPSC rise times do not change during $\mathrm{ON} / \mathrm{OFF}$ sublamination. EPSCs were recorded at $+40 \mathrm{mV}$. $A$, Average sEPSCs from a P16 cell (top) and a P29 cell (bottom) in control (black trace) and CNQX (gray trace) conditions. $B$, The normalized rise time (rise time/amplitude) of sEPSCs is slightly increased in the presence of CNQX; however, the effect is similar in both younger (filled bar) and older (open bar) cells. $C$, Optic tract-evoked EPSCs from a P16 cell (top) and a P28 cell (bottom). D, The normalized rise time of optic tractevoked EPSCs is increased under CNQX, but the effect is again similar in the younger ( filled bar) and older (open bar) cells. Diamonds indicate median values. 


\section{A. NR1 + GluR1}
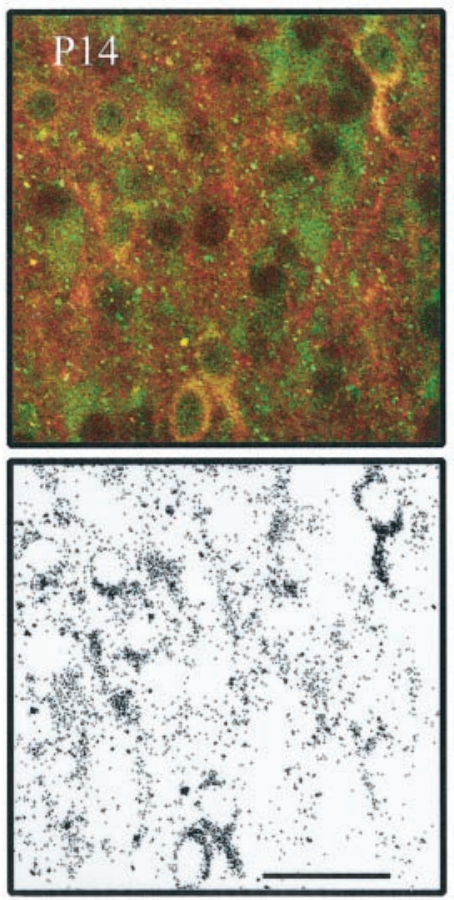
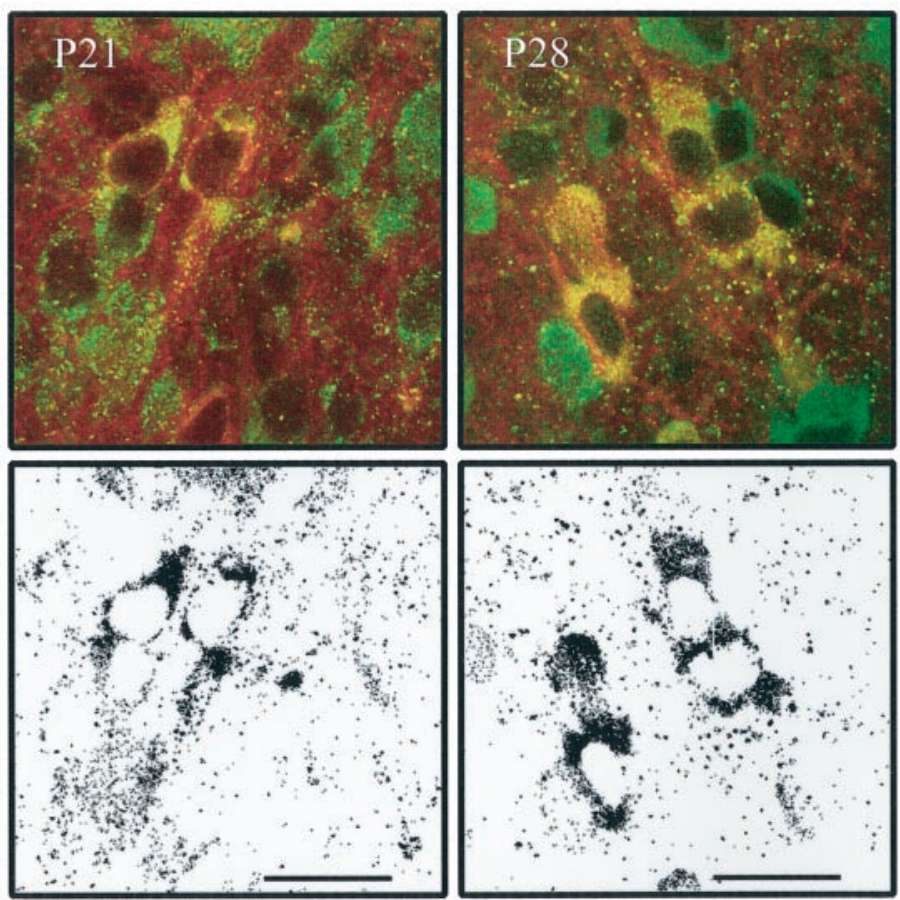

\section{B. Colocalization}

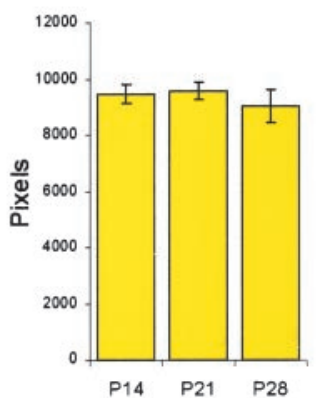

\section{Clustering}
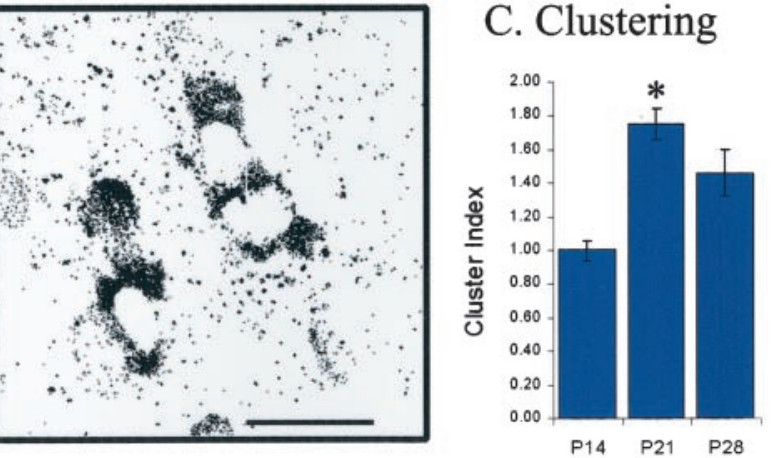

Figure 6. AMPA and NMDA receptor subunit colocalization is stable over ON/OFF sublamination. $A$, NR1 (NMDA) and GluR1 (AMPA) subunit expression and colocalization at P14 $(n=15$ images from 2 animals), P21 ( $n=22$ images from 4 animals), and P28 ( $n=14$ images from 3 animals). Top row shows examples of labeling of NR1 (green) and GluR1 (red) through ON/OFF sublamination. Colocalized labeling is shown in yellow. Bottom row shows only the colocalized labeling from the corresponding row above. B, Colocalization remains constant from P14 to P28 ( $p>0.05)$. $C$, The clustering of colocalized pixels is similar before and after sublamination $(p>0.05)$, although it increases during the third postnatal week $(p<0.05)$. Scale bar (in this and all subsequent figures), $25 \mu \mathrm{m}$.

\section{A. NR1 + GluR4}
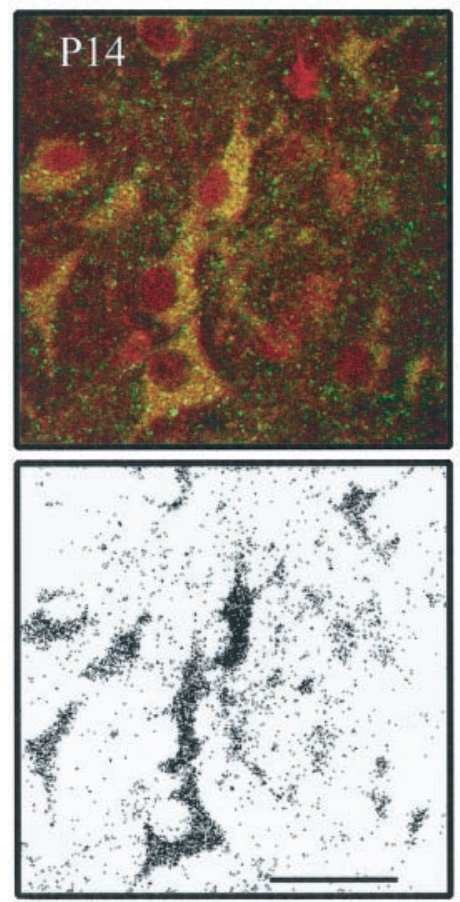
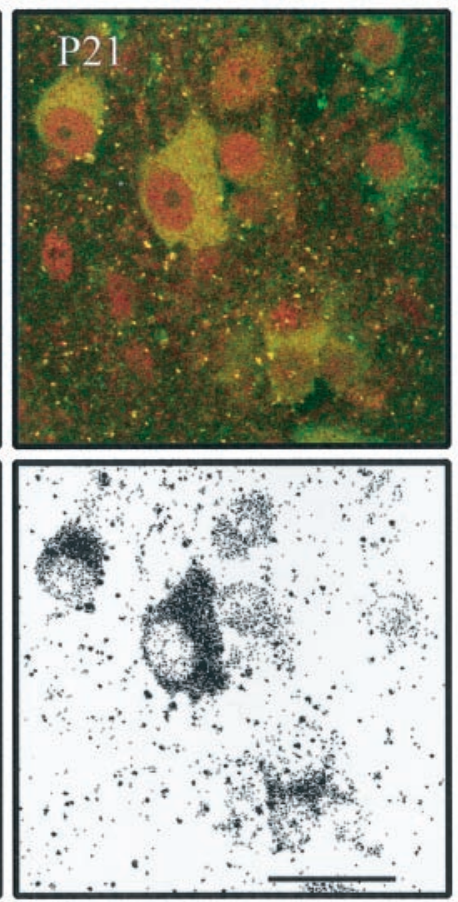
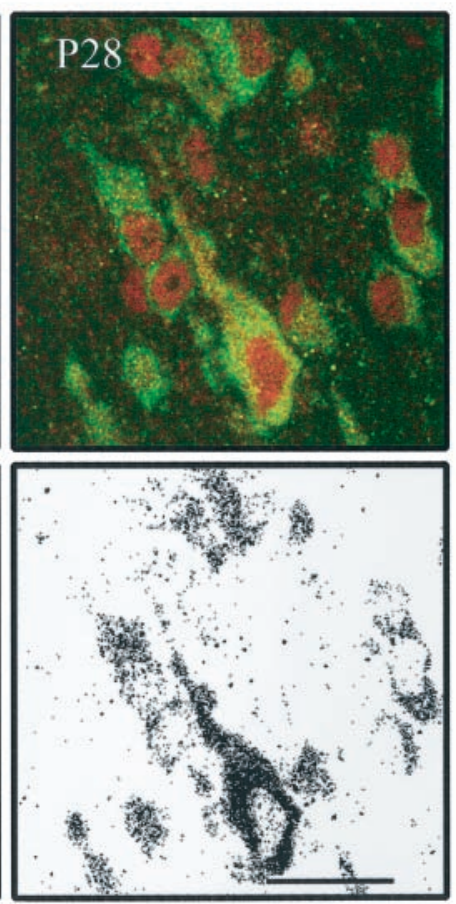

\section{B. Colocalization}

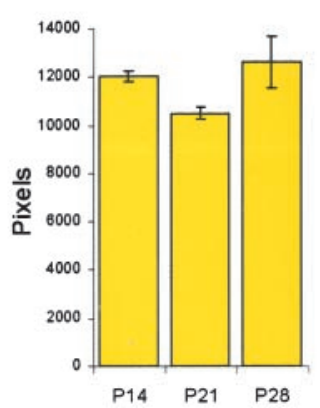

\section{Clustering}

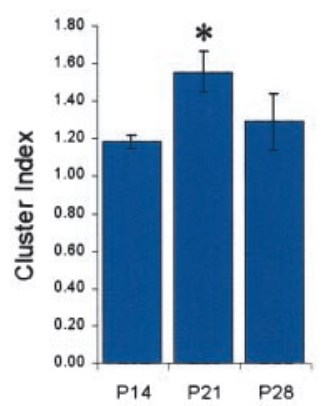

Figure 7. The pattern of AMPA-NMDA colocalization is not unique to GluR1. $A-C$, Same convention as in Figure 6. GluR4-NR1 colocalization is stable across ON/OFF sublamination ( $p>0.05)$. P14 $(n=14$ images from 2 animals), P21 $(n=13$ images from 4 animals), and P28 $(n=11$ images from 3 animals). Clustering of colocalized pixels is similar before and after sublamination $(p>0.05)$, although it increases during the third postnatal week $(p<0.05)$. 


\section{A. CTB + NR1 + GluR1}
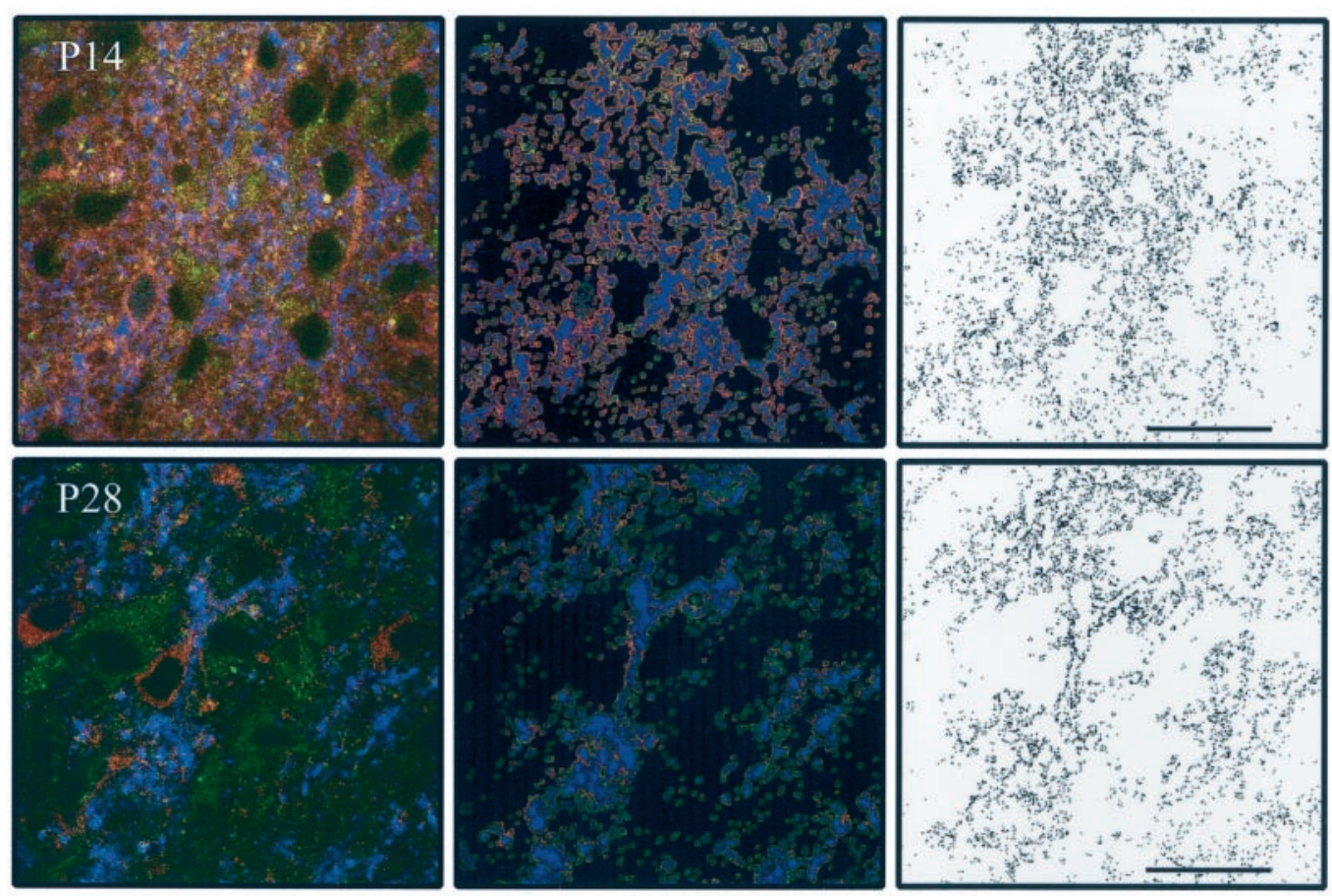

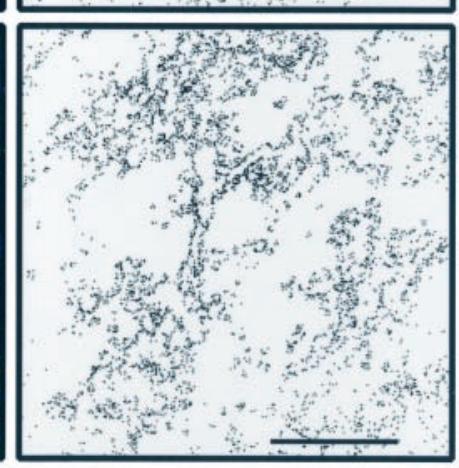

\section{B. Colocalization}

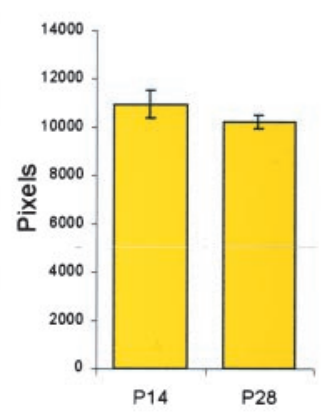

\section{Clustering}

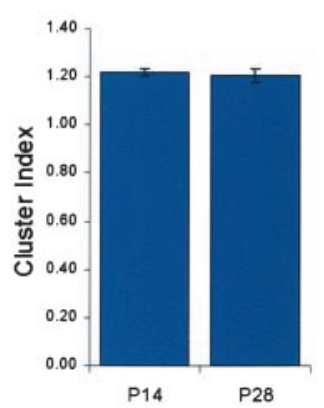

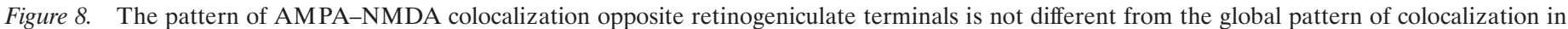

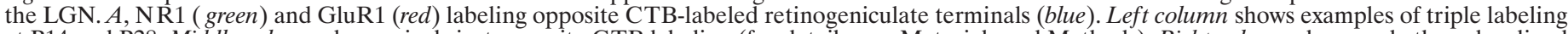

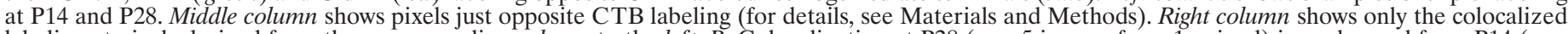

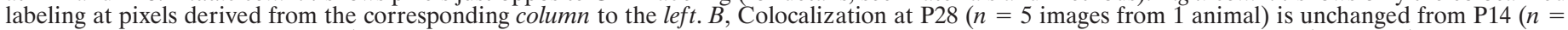
8 images from 1 animal; $p>0.05)$. $C$, Likewise, the clustering of colocalized pixels is similar before and after sublamination $(p>0.05)$.

Finally, we were interested in examining NR1, GluR1, and GluR4 staining that was closely associated with retinal terminals. That is, given the concern noted above that both intracellular and extracellular subunits were labeled, we wanted to characterize colocalization directly opposite retinogeniculate boutons (i.e., at presumptive retinal synapses). To that end, we performed triplelabeling experiments. We labeled retinogeniculate afferents with CTB injected into the eye and subsequently also labeled GluR1 and NR1 subunits (Fig. 8A). These experiments also distinguished between retinogeniculate and corticogeniculate inputs and allowed for the determination of whether an increase in AMPA-NMDA colocalization at retinogeniculate synapses was being masked by the more extensive corticogeniculate input. Colocalization opposite CTB-stained retinogeniculate fibers revealed a pattern that was not significantly different from that seen with the more general double labeling. Both colocalization and clustering were no different after ON/OFF sublamination than before $(n=13$ images from 2 animals; $p>0.05$ ) (Fig. $8 B, C$ ). Triple-labeling of retinogeniculate terminals, GluR4, and NR1 (Fig. $9 A$ ) showed the same results as with GluR1; colocalization and clustering opposite retinogeniculate terminals were similar before and after ON/OFF sublamination ( $n=10$ images from 2 animals; $p>0.05$ ) (Fig. 9B,C).

In separate experiments, we confirmed that primarily synaptic boutons at retinal terminals rather than fibers of passage were labeled by the CTB injections. In conjunction with CTB injections, we labeled synaptophysin, a synaptic vesicle protein. The vast majority of CTB label (98\%) was colocalized with synaptophysin (Fig. 9D), indicating that the periphery of CTB label was an appropriate constraint for examining presumptive postsynaptic locations for GluR1 (or GluR4)-NR1 colocalization. Whereas there was very little CTB label that was not colocalized with synaptophysin, there was, of course, synaptophysin labeling that was not colocalized with CTB (52\% of the label in Fig. 9D), reflecting the nonretinal input to the LGN (e.g., cortical and brainstem terminals).

\section{DISCUSSION}

The results presented here, obtained using a variety of techniques, demonstrate that, although a small number of silent retinogeniculate synapses are present at the onset of ON/OFF sublamination, an overall change in the AMPA/NMDA contribution is unlikely to be involved in the maturation of sublamination. Using minimal stimulation of the optic tract, we show that failure rates of responses at depolarized potentials do not change with age. We show that NMDA-mediated sEPSCs maintain their size and kinetics and have shown previously the same for AMPA-mediated sEPSCs (Hohnke and Sur, 1999c). We demonstrate that the rise time and amplitude of the NMDA-mediated component of spontaneous and optic tract-evoked EPSCs is constant throughout ON/OFF sublamination. Using immunocytochemistry to identify AMPA and NMDA receptor subunits, we show that AMPA-NMDA colocalization is stable throughout the LGN and opposite retinogeniculate terminals in particular.

Three caveats to our data should be noted. First, it is possible that NMDA-only currents are not attributable to the existence of NMDA-only synapses but rather to the spillover of glutamate from an active synapse into an inactive one (Kullmann and Asztely, 1998). The low concentration of transmitter that would result from spillover would preferentially activate NMDA receptors, which have a higher affinity for glutamate (Patneau and Mayer, 1990). However, recent evidence suggests that AMPA and NMDA receptors have similar affinities (Dube and Liu, 1999). Additionally, immunocytochemical data show that some hippocampal synapses have no detectable AMPA receptors (Liao et al., 1999; Petralia et al., 1999). Recordings from autapses also reveal silent synapses (Gomperts et al., 1998), and the kinetics of NMDA receptor activation at functional and silent synapses are similar (Rumpel et al., 1998). Whatever the source of NMDA-only currents, our results indicate that their contribution to retinogeniculate transmission is held fixed throughout ON/OFF sublamination. 


\section{A. CTB + NR1 + GluR4}
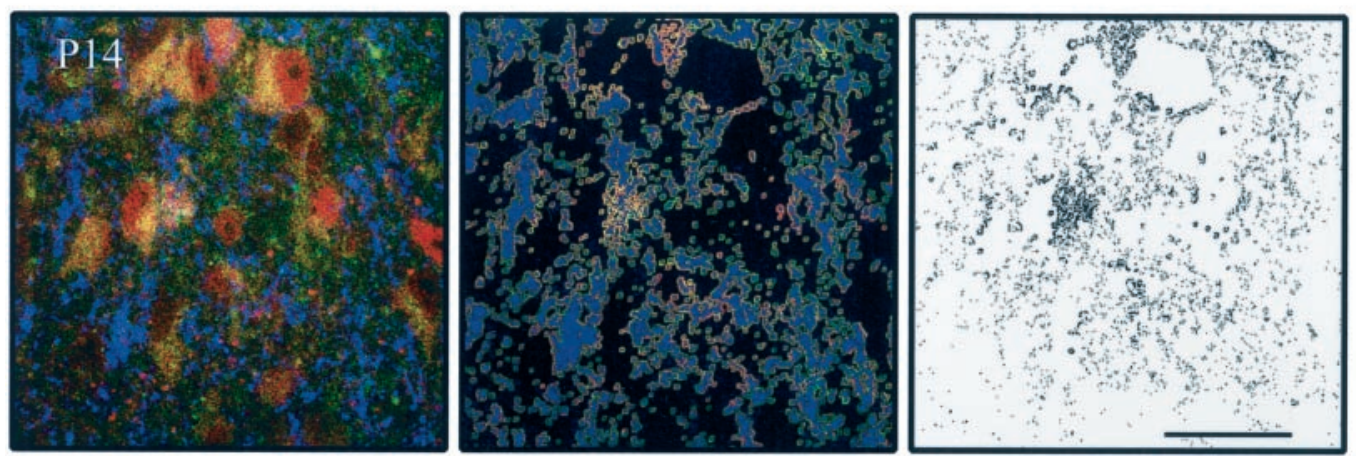

B. Colocalization

C. Clustering
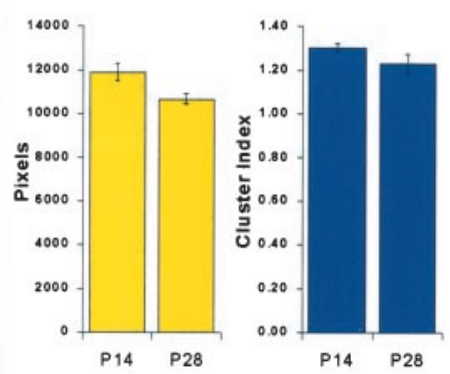

D. CTB+Synaptophysin
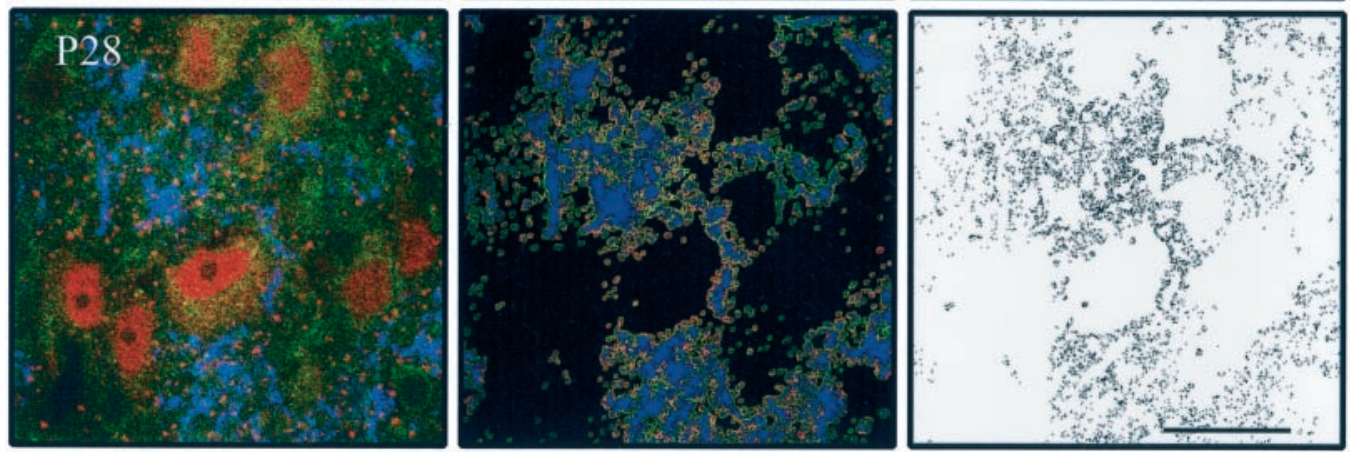

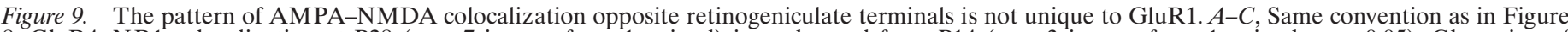

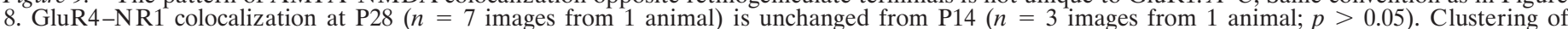

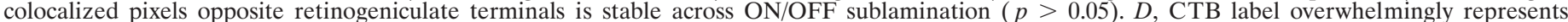

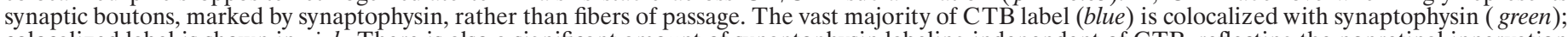

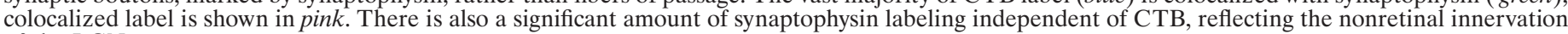
of the LGN.

Second, we recorded from a heterogeneous population of cells in the A layers of the LGN that include X cells, Y cells, and interneurons. It is unlikely that we recorded from many interneurons; recordings from cells with small somas [which are characteristic of interneurons (Friedlander et al., 1981)] were avoided, and all cells included in the analysis displayed easily evoked low-threshold calcium spikes, a characteristic of LGN relay cells (McCormick and Pape, 1988). However, although we observed no systematic variations in our data that might correlate with different LGN cell types, such a relationship cannot be excluded.

A third caveat is that, ideally, our immunostaining technique would target extracellular receptor proteins opposite retinogeniculate terminals. Antibodies to extracellular domains are available (Mammen et al., 1997), of course, that specificity would be lost in the sectioned LGNs that we used in this study because of the permeability of cell membranes attributable to tissue sectioning. As a result, trends in the colocalization of subunits at synapses may be masked by the characteristics of intracellular colocalization. Indeed, in spinal cultures, the percentage of surface GluR1 increases as cells mature during the first 1-2 weeks (Mammen et al., 1997). However, our cluster analysis indicates, albeit indirectly, that in P14-P28 ferret LGN there is no trend in the density of colocalization at particular loci (e.g., the nuclei) that would obscure an increase in colocalization after ON/OFF sublamination relative to before it. A more direct analysis of colocalization just opposite identified retinogeniculate fibers gives the same results, i.e., stable colocalization throughout $\mathrm{ON} / \mathrm{OFF}$ sublamination. We did observe an increase in clustering during the middle of sublamination that may reflect a transient increase in receptor subunit production in the soma.

\section{Silent synapses and their role in development of connections}

Our findings present a counterweight to recent evidence suggesting that the conversion of silent to functional synapses may play an important role in the development and refinement of inputs (Durand et al., 1996; Wu et al., 1996; Isaac et al., 1997; Li and Zhuo, 1998; Rumpel et al., 1998; Liao et al., 1999; Petralia et al., 1999). Of that evidence, only one previous study (Isaac et al., 1997) has investigated the development of silent synapses in a mammalian system, the rat primary somatosensory cortex, in which activitydependent plasticity has been systematically explored. Yet, even in that system, the role of activity in reshaping the thalamocortical afferents that were probed for silent synapses is unresolved (Feldman et al., 1999; Wallace and Fox, 1999). The development of the ON/OFF sublaminae, and more specifically, the development of individual retinogeniculate axons, are known to depend on retinal activity (Cramer and Sur, 1997), NMDA receptors on LGN cells (Hahm et al., 1991, 1999), and the presence of nitric oxide (Cramer et al., 1996; Cramer and Sur, 1999). The present results demonstrate that, although the structure of retinogeniculate arbors is altered during sublamination in an activity-dependent manner, the functional efficacy of retinogeniculate synapses does not appear to change during this period.

Why might the results at retinogeniculate and thalamocortical synapses differ? It is possible that there are simply different mechanisms of plasticity at work in these two systems. Even within one system, distinct forms of plasticity can be found (Zalutsky and Nicoll, 1991; Johnston et al., 1992). It is also possible that differences between the cellular environments of 1-week-old rat cortex and 4-week-old ferret thalamus recruit the same elements (silent synapses) for different purposes (Constantine-Paton and Cline, 1998; Lin and Constantine-Paton, 1998). Indeed, in amphibians in which the activity-dependence of retinotectal afferents has been extensively described previously (Debski et al., 1990; Cline, 1991; Renteria and Constantine-Paton, 1996), it has been proposed that silent synapses provide a mechanism for the continued, faithful transmission of information during the period when topography must be continually updated (Wu et al., 1996). Perhaps the rapidly 
developing body surface of neonatal rats places demands on thalamocortical afferents in the somatosensory cortex that are similar to those placed on retinotectal afferents in Xenopus tadpoles in response to the addition of RGCs. In the ferret, retinal ganglion cell birth is completed by P3 (Johnson and Casagrande, 1993), and ganglion cell numbers reach adult values by P6 (Henderson et al., 1988; Johnson and Casagrande, 1993), well before the onset of ON/OFF sublamination.

However, it is also possible that the results presented here and those reported from thalamocortical synapses (Isaac et al., 1997) do not, in fact, differ greatly. These authors note that the reduction in the percentage of silent synapses that they observe may be the result of a sampling bias at later ages after significant (functional) synaptogenesis has occurred. That is, if the new terminations that form during late axon growth primarily contain both AMPA and NMDA receptors, then the percentage of silent synapses would decrease. The width of thalamocortical axon arbors in the somatosensory cortex increases by $80 \%$ or more during the period investigated (Catalano et al., 1996). In contrast, retinogeniculate arbors do not increase significantly in size during ON/OFF sublamination, although they do become progressively restricted to an LGN sublayer (Hahm et al., 1999).

Consistent with our finding that the AMPA/NMDA contribution is held constant during ON/OFF sublamination in the LGN are reports that silent synapses persist during early development in another part of the thalamus, the ventroposterior nucleus (Golshani and Jones, 1999), and in the dorsal horn of the rat spinal cord (Bardoni et al., 1998) (but see Li and Zhuo, 1998). Additionally, like the results reported here, sEPSCs in the rat cortex consist of both AMPA and NMDA receptor-mediated currents, and their ratio is constant throughout early development (Burgard and Hablitz, 1993). In rat cortical neurons in culture, the ratio of quantal AMPA/NMDA currents is similar at different synapses on the same neuron, and the ratio is preserved after activity-dependent changes in synaptic strength (Watt et al., 2000). In some systems AMPA receptors develop earlier than NMDA receptors (Gordon et al., 1997; Colwell et al., 1998; Rohrbough and Spitzer, 1999). Perhaps more analogously to our data, NMDA-mediated sEPSC amplitudes and rise times show no age-dependent changes in the rat superior colliculus during the time when retinocollicular axons are refining (Hestrin, 1992; Shi et al., 1997). However, in that system, NMDA-mediated sEPSC decay times decrease during map refinement, although our results show no such change in the ferret. This difference is likely attributable to the difference in timing of a developmental shift from NR2B to NR2A NMDA receptor subunits. Our study encompasses the entirety of ON/OFF sublamination, but the NR2B to NR2A shift in the LGN does not occur until well thereafter (Ramoa and Prusky, 1997), in parallel with the decrease in the decay times of evoked NMDA-mediated EPSCs (Ramoa and McCormick, 1994b). In contrast, the NR2B to NR2A shift in the rat superior colliculus, and a parallel decrease in the decay times of NMDA-mediated sEPSCs, occur within the time period examined in those studies (Shi et al., 1997).

If not as mediators of axon branch stabilization, what then is the role of NMDA-only synapses? Silent synapses may not in fact be silent; extracellular glutamate concentrations (Lerma et al., 1986) and low-threshold activation of NMDA receptors in vivo (Fox et al., 1990) suggest that they may be a functional element of developing or mature circuits (Constantine-Paton and Cline, 1998). Alternatively, if NMDA-only synapses are primarily silent, they may act as synapses-in-reserve or as mediators of gain control (Malgaroli, 1999). In any case, the results presented here reinforce the assessment of the function of the population of retinogeniculate synapses as remarkably stable during a period of intense anatomical reorganization of their input (Hohnke and Sur, 1999c). Synaptic properties of geniculocortical afferents in the cat also show surprising conservation during an intense period of reorganization (Silver and Stryker, 1999), and in the mouse visual cortex, normal plasticity occurs despite defects in the ability to potentiate synaptic efficacy (Hensch et al., 1998). The developing visual system may rely on cues other than changes in synaptic efficacy, perhaps via neurotrophic regulation (Castren et al., 1992; Allendoerfer et al., 1994; Cabelli et al., 1995; Riddle et al., 1995; McAllister et al., 1996), to mediate axon branch withdrawal and stabilization. Alternatively, synaptic efficacy may be modulated indirectly. Recent evidence suggests that absolute synaptic efficacy could remain constant, whereas relative synaptic efficacy is modulated by activity-dependent changes in the intrinsic excitability of neurons (Desai et al., 1999; Stemmler and Koch, 1999) or in the connectivity of cell pairs (Hsia et al., 1998). Indeed, the development of retinogeniculate connections is accompanied by significant changes in the intrinsic membrane properties of LGN neurons (White and Sur, 1992; Ramoa and McCormick, 1994a; Hohnke and Sur, 1999c).

\section{REFERENCES}

Allendoerfer K, Cabelli R, Escandon E, Kaplan D, Nikolics K, Shatz C (1994) Regulation of neurotrophin receptors during the maturation of the mammalian visual system. J Neurosci 14:1795-1811.

Angelucci A, Clasca F, Sur M (1996) Anterograde axonal tracing with the subunit B of cholera toxin: a highly sensitive immunohistochemical protocol for revealing fine axonal morphology in adult and neonatal brains. J Neurosci Methods 65:101-112.

Bardoni R, Magherini PC, MacDermott AB (1998) NMDA EPSCs at glutamatergic synapses in the spinal cord dorsal horn of the postnatal rat. J Neurosci 18:6558-6567.

Burgard E, Hablitz J (1993) NMDA receptor-mediated components of miniature excitatory synaptic currents in developing rat neocortex. J Neurophysiol 70:1841-1852.

Cabelli R, Hohn A, Shatz C (1995) Inhibition of ocular dominance column formation by infusion of NT-4/5 of BDNF. Science 267:1662-1666.

Carder R (1997) Immunocytochemical characterization of AMPAselective glutamate receptor subunits: laminar and compartmental distribution in macaque striate cortex. J Neurosci 17:3352-3363.

Castren E, Zafra F, Thoenen H, Lindholm D (1992) Light regulates expression of brain-derived neurotrophic factor mRNA in rat visual cortex. Proc Natl Acad Sci USA 89:9444-9448.

Catalano S, Robertson R, Killackey H (1996) Individual axon morphology and thalamocortical topography in developing rat somatosensory cortex. J Comp Neurol 367:36-53.

Cline H (1991) Activity-dependent plasticity in the visual systems of frogs and fish. Trends Neurosci 14:104-111.

Colwell CS, Cepeda C, Crawford C, Levine MS (1998) Postnatal development of glutamate receptor-mediated responses in the neostriatum. Dev Neurosci 20:154-163.

Constantine-Paton M, Cline HT (1998) LTP and activity-dependent synaptogenesis: the more alike they are, the more different they become. Curr Opin Neurobiol 8:139-148.

Constantine-Paton M, Cline H, Debski E (1990) Patterned activity, synaptic convergence, and the NMDA receptor in developing visual pathways. Annu Rev Neurosci 13:129-154.

Cramer KS, Sur M (1995) Activity-dependent remodeling of connections in the mammalian visual system. Curr Opin Neurobiol 5:106-111.

Cramer KS, Sur M (1997) Blockade of afferent impulse activity disrupts on/off sublamination in the ferret lateral geniculate nucleus. Dev Brain Res 98:287-290.

Cramer KS, Sur M (1999) The neuronal form of nitric oxide synthase is required for pattern formation by retinal afferents in the ferret lateral geniculate nucleus. Brain Res Dev Brain Res 116:79-86.

Cramer KS, Angelucci A, Hahm JO, Bogdanov MB, Sur M (1996) A role for nitric oxide in the development of the ferret retinogeniculate projection. J Neurosci 16:7995-8004.

Debski EA, Cline HT, Constantine-Paton M (1990) Activity-dependent tuning and the NMDA receptor. J Neurobiol 21:18-32.

Desai N, Rutherford L, Turrigiano G (1999) Plasticity in the intrinsic excitability of cortical pyramidal neurons. Nat Neurosci 2:515-520.

Dube G, Liu G (1999) AMPA and NMDA receptors display similar affinity during rapid synaptic-like glutamate applications. Soc Neurosci Abstr 25:992.

Durand GM, Kovalchuk Y, Konnerth A (1996) Long-term potentiation and functional synapse induction in developing hippocampus. Nature 381:71-75.

Feldman DE, Nicoll RA, Malenka RC (1999) Synaptic plasticity at thalamocortical synapses in developing rat somatosensory cortex: LTP, LTD, and silent synapses. J Neurobiol 41:92-101.

Fox K, Sato H, Daw N (1990) The effect of varying stimulus intensity on NMDA-receptor activity in cat visual cortex. J Neurophysiol 64:1413-1428.

Friedlander M, Lin G, Stanford L, Sherman S (1981) Morphology of functionally identified neurons in the lateral geniculate nucleus of the cat. J Neurophysiol 46:80-129.

Goda Y, Stevens C (1994) Two components of transmitter release at a central synapse. Proc Natl Acad Sci USA 91:12942-12946.

Golshani P, Jones E (1999) Synchronized paroxysmal activity in the de- 
veloping thalamocortical network mediated by corticothalamic projections and "silent" synapses. J Neurosci 19:2865-2875.

Gomperts S, Rao A, Craig A, Malenka R, Nicoll R (1998) Postsynaptically silent synapses in single neuron cultures. Neuron 21:1443-1451.

Goodman C, Shatz C (1993) Developmental mechanisms that generate precise patterns of neuronal connectivity. Cell 72:77-98.

Gordon B, Kinch G, Kato N, Keele C, Lissman T, Fu LN (1997) Development of MK-801, kainate, AMPA, and muscimol binding sites and the effect of dark rearing in rat visual cortex. J Comp Neurol 383:73-81.

Hahm JO, Langdon RB, Sur M (1991) Disruption of retinogeniculate afferent segregation by antagonists to NMDA receptors. Nature 351:568-570.

Hahm JO, Cramer KS, Sur M (1999) Pattern formation by retinal afferents in the ferret lateral geniculate nucleus: developmental segregation and the role of $N$-methyl-D-aspartate receptors. J Comp Neurol 411:327-345.

Hamos JE, Van Horn SC, Raczkowski D, Sherman SM (1987) Synaptic circuits involving an individual retinogeniculate axon in the cat. J Comp Neurol 259:165-192.

Henderson Z, Finlay B, Wikler K (1988) Development of ganglion cell topography in ferret retina. J Neurosci 8:1194-1205.

Hensch TK, Gordon JA, Brandon EP, McKnight GS, Idzerda RL, Stryker MP (1998) Comparison of plasticity in vivo and in vitro in the developing visual cortex of normal and protein kinase A RI $\beta$-deficient mice. J Neurosci 18:2108-2117.

Hestrin S (1992) Developmental regulation of NMDA receptor-mediated synaptic currents at a central synapse. Science 357:686-689.

Hohnke C, Sur M (1999a) Development of the visual pathways: effects of neural activity. Ment Retard Dev Disabil Res Rev 5:51-59.

Hohnke C, Sur M (1999b) The number and efficacy of single retinal axon inputs to cells in the ferret lateral geniculate nucleus during the development of ON/OFF sublamination. Soc Neurosci Abstr 25:1267.

Hohnke C, Sur M (1999c) Stable properties of spontaneous EPSCs and miniature retinal EPSCs during the development of ON/OFF sublamination in the ferret lateral geniculate nucleus. J Neurosci 19:236-247.

Hsia A, Malenka R, Nicoll R (1998) Development of excitatory circuitry in the hippocampus. J Neurophysiol 79:2013-2024.

Isaac J, Nicoll R, Malenka R (1995) Evidence for silent synapses: implications for the expression of LTP. Neuron 15:427-434.

Isaac J, Crair M, Nicoll R, Malenka R (1997) Silent synapses during development of thalamocortical inputs. Neuron 18:269-280.

Johnson J, Casagrande V (1993) Prenatal development of axon outgrowth and connectivity in the ferret visual system. Vis Neurosci 10:117-130.

Johnston D, Williams S, Jaffe D, Gray R (1992) NMDA-receptorindependent long-term potentiation. Annu Rev Physiol 54:489-505.

Jones E, Tighilet B, Tran B, Huntsman M (1998) Nucleus- and cell-specific expression of NMDA and non-NMDA receptor subunits in monkey thalamus. J Comp Neurol 397:371-393.

Kandel E, O'Dell T (1992) Are adult learning mechanisms also used for development? Science 258:243-245.

Katz L, Shatz C (1996) Synaptic activity and the construction of cortical circuits. Science 274:1133-1138.

Kullmann D, Asztely F (1998) Extrasynaptic glutamate spillover in the hippocampus: evidence and implications. Trends Neurosci 21:8-14.

Lerma J, Herranz AS, Herreras O, Abraira V, Martin del Rio R (1986) In vivo determination of extracellular concentration of amino acids in the rat hippocampus. A method based on brain dialysis and computerized analysis. Brain Res 384:145-155.

Li P, Zhuo M (1998) Silent glutamatergic synapses and nociception in mammalian spinal cord. Nature 393:695-698.

Liao D, Hessler N, Malinow R (1995) Activation of postsynaptically silent synapses during pairing-induced LTP in CA1 region of hippocampal slice. Nature 375:400-404.

Liao D, Zhang X, O'Brien R, Ehlers M, Huganir R (1999) Regulation of morphological postsynaptic silent synapses in developing hippocampal neurons. Nat Neurosci 2:37-43.

Lin SY, Constantine-Paton M (1998) Suppression of sprouting: an early function of NMDA receptors in the absence of AMPA/kainate receptor activity. J Neurosci 18:3725-3737.

Malgaroli A (1999) Silent synapses: I can’t hear you! Could you please speak aloud? Nat Neurosci 2:3-5.

Mammen AL, Huganir RL, O'Brien RJ (1997) Redistribution and stabilization of cell surface glutamate receptors during synapse formation. J Neurosci 17:7351-7358.

McAllister A, Katz L, Lo D (1996) Neurotrophin regulation of cortical dendritic growth requires activity. Neuron 17:1057-1064.

McCormick D, Pape H (1988) Acetylcholine inhibits identified interneurons in the cat lateral geniculate nucleus. Nature 334:246-248.
Miledi R (1966) Strontium as a substitute for calcium in the process of transmitter release at the neuromuscular junction. Nature 212:1233-1234.

Oliet SH, Malenka RC, Nicoll RA (1996) Bidirectional control of quantal size by synaptic activity in the hippocampus. Science 271:1294-1297.

Oray S, Hohnke C, Sur M (1999) The ratio of AMPA to NMDA receptors in the ferret lateral geniculate nucleus during the development of $\mathrm{ON} /$ OFF sublamination. Soc Neurosci Abstr 25:1267.

Patneau D, Mayer M (1990) Structure-activity relationships for amino acid transmitter candidates acting at $N$-methyl-D-aspartate and quisqualate receptors. J Neurosci 10:2385-2399.

Petralia R, Esteban J, Wang Y, Partridge J, Z hao H, Wenthold R, Malinow R (1999) Selective acquisition of AMPA receptors over postnatal development suggests a molecular basis for silent synapses. Nat Neurosci 2:31-36.

Raastad M, Storm J, Andersen P (1992) Putative single quantum and single fiber excitatory postsynaptic currents show similar amplitude, range and variability in rat hippocampal slices. Eur J Neurosci 4:113-117.

Ramoa A, McCormick D (1994a) Developmental changes in electrophysiological properties of LGNd neurons during reorganization of retinogeniculate connections. J Neurosci 14:2089-2097.

Ramoa A, McCormick D (1994b) Enhanced activation of NMDA receptor responses at the immature retinogeniculate synapse. J Neurosci 14:2098-2105.

Ramoa A, Prusky G (1997) Retinal activity regulates developmental switches in functional properties and ifenprodil sensitivity of NMDA receptors in the lateral geniculate nucleus. Brain Res Dev Brain Res 101:165-175.

Renteria RC, Constantine-Paton M (1996) Exogenous nitric oxide causes collapse of retinal ganglion cell axonal growth cones in vitro. J Neurobiol 29:415-428.

Riddle D, Lo D, Katz L (1995) NT-4-mediated rescue of lateral geniculate neurons from effects of monocular deprivation. Nature 378:189-191.

Rohrbough J, Spitzer NC (1999) $\mathrm{Ca}^{2+}$-permeable AMPA receptors and spontaneous presynaptic transmitter release at developing excitatory spinal synapses. J Neurosci 19:8528-8541.

Rumpel S, Hatt H, Gottmann K (1998) Silent synapses in the developing rat visual cortex: evidence for postsynaptic expression of synaptic plasticity. J Neurosci 18:8863-8874.

Ruthazer E, Stryker M (1996) The role of activity in the development of long-range horizontal connections in area 17 of the ferret. J Neurosci 16:7253-7269.

Sherman S, Koch C (1986) The control of retinogeniculate transmission in the mammalian lateral geniculate nucleus. Exp Brain Res 63:1-20.

Sherman S, Koch C (1998) Thalamus. In: The synaptic organization of the brain, Ed 4 (Shepherd G, ed), pp 289-328. New York: Oxford UP.

Shi J, Aamodt S, Constantine-Paton M (1997) Temporal correlations between functional and molecular changes in NMDA receptors and GABA neurotransmission in the superior colliculus. J Neurosci 17:6264-6276.

Silver M, Stryker M (1999) Synaptic density in geniculocortical afferents remains constant after monocular deprivation in the cat. J Neurosci 19:10829-10842.

Stelzer EHK (1995) The intermediate optical system of laser-scanning confocal microscopes. In: Handbook of biological confocal microscopy, Ed 2 (Pawley JB, ed), pp 139-154. New York: Plenum.

Stemmler M, Koch C'(1999) How voltage-dependent conductances can adapt to maximize the information encoded by neuronal firing rate. Nat Neurosci 6:521-527.

Stevens C, Wang Y (1994) Changes in reliability of synaptic function as a mechanism for plasticity. Nature 371:704-707.

Voigt T, De Lima A, Beckmann M (1993) Synaptophysin immunohistochemistry reveals inside-out pattern of early synaptogenesis in ferret cerebral cortex. J Comp Neurol 330:48-64.

Wallace H, Fox K (1999) Local cortical interactions determine the form of cortical plasticity. J Neurobiol 41:58-63.

Watt AJ, van Rossum MC, MacLeod KM, Nelson SB, Turrigiano GG (2000) Activity coregulates quantal AMPA and NMDA currents at neocortical synapses. Neuron 26:659-670.

White C, Sur M (1992) Membrane and synaptic properties of developing lateral geniculate nucleus neurons during retinogeniculate axon segregation. Proc Natl Acad Sci USA 89:9850-9854.

Wilson JR, Friedlander MJ, Sherman SM (1984) Fine structural morphology of identified X- and Y-cells in the cat's lateral geniculate nucleus. Proc R Soc Lond B Biol Sci 221:411-436.

Wu G, Malinow R, Cline H (1996) Maturation of a central glutamatergic synapse. Science 274:972-976.

Zalutsky R, Nicoll R (1991) Comparison of two forms of long-term potentiation in single hippocampal neurons. Science 248:1619-1624. 